\title{
AFIP-6 Fabrication Summary Report
}

Glenn Moore M. Craig Marshall

September 2011

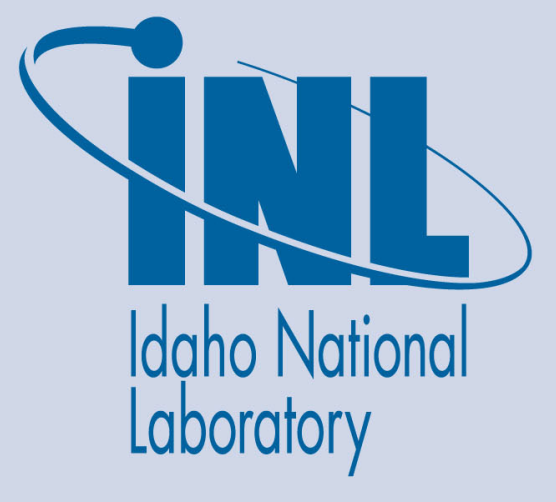

The INL is a U.S. Department of Energy National Laboratory operated by Battelle Energy Alliance 


\section{DISCLAIMER}

This information was prepared as an account of work sponsored by an agency of the U.S. Government. Neither the U.S. Government nor any agency thereof, nor any of their employees, makes any warranty, expressed or implied, or assumes any legal liability or responsibility for the accuracy, completeness, or usefulness, of any information, apparatus, product, or process disclosed, or represents that its use would not infringe privately owned rights. References herein to any specific commercial product, process, or service by trade name, trade mark, manufacturer, or otherwise, does not necessarily constitute or imply its endorsement, recommendation, or favoring by the U.S. Government or any agency thereof. The views and opinions of authors expressed herein do not necessarily state or reflect those of the U.S. Government or any agency thereof. 
INL/EXT-11-21655

\title{
AFIP-6 Fabrication Summary Report
}

\author{
Glenn Moore \\ M. Craig Marshall
}

September 2011

\section{Idaho National Laboratory \\ Idaho Falls, Idaho 83415}

http://www.inl.gov

\author{
Prepared for the
}

U.S. Department of Energy

Office of National Nuclear Security Administration

Under DOE Idaho Operations Office

Contract DE-AC07-05ID14517 

AFIP-6 Fabrication Summary Report

INL/EXT-11-21655

September 2011
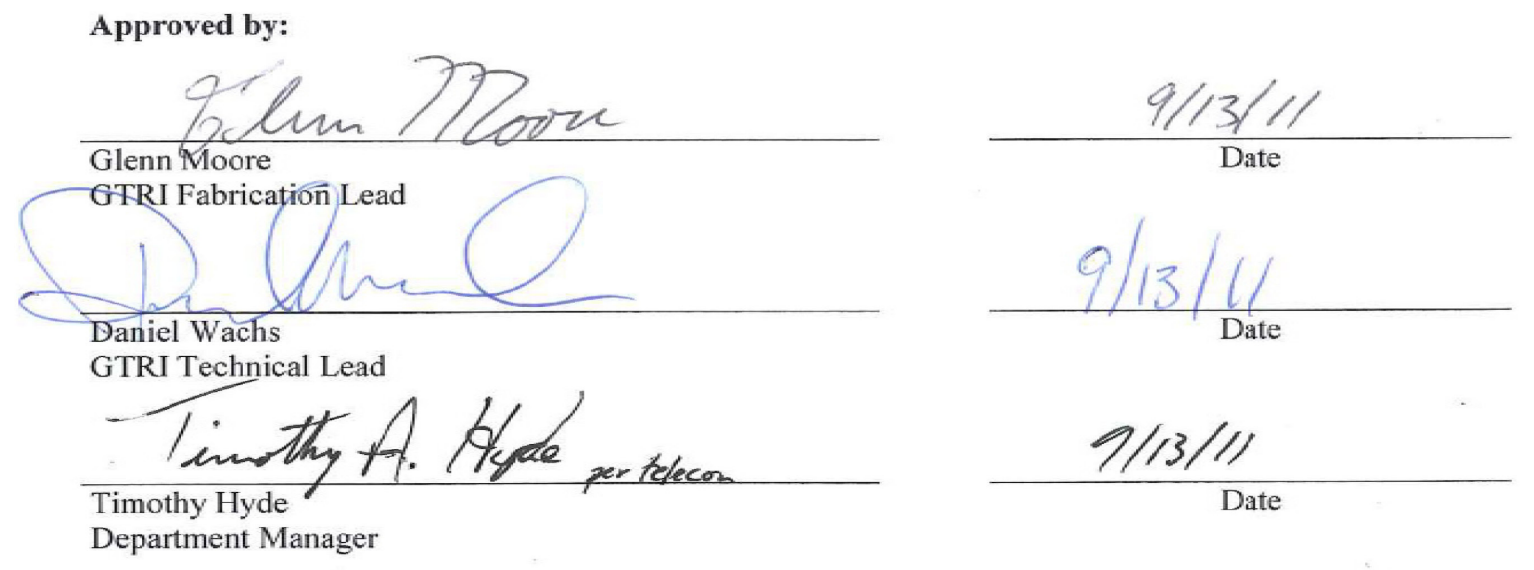


\section{CONTENTS}

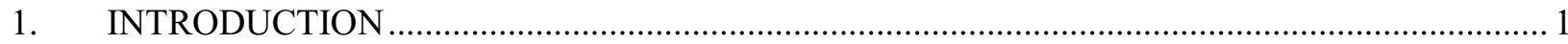

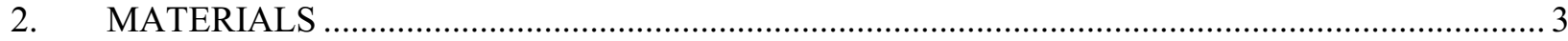

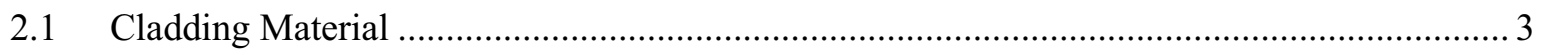

2.2 Zirconium Diffusion Barrier Material................................................................................... 3

3. FOIL FABRICATION OF ZR CO-ROLLED FOILS ............................................................. 4

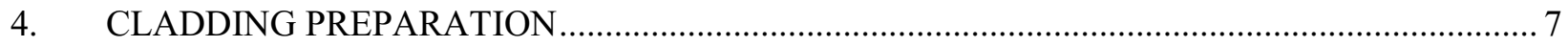

5. HIP PROCESSING FUEL PLATE FABRICATION …........................................................ 7

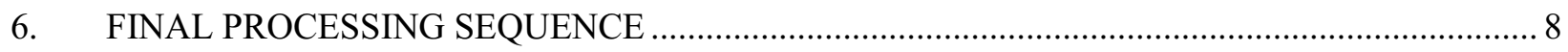

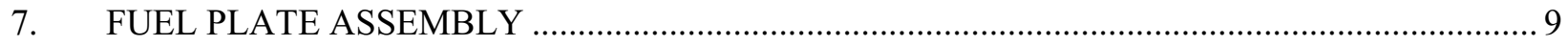

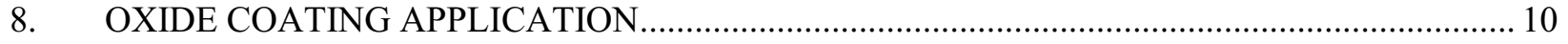

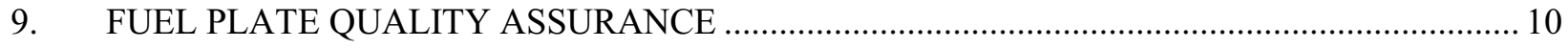

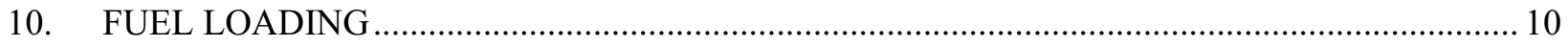

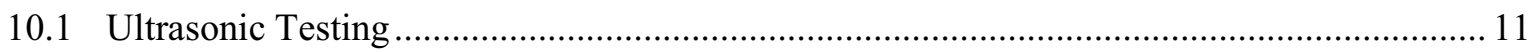

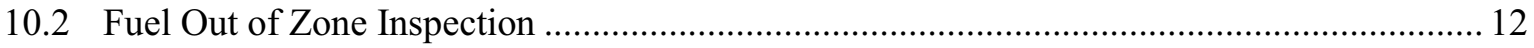

10.3 Dimensional, Surface, and Cleanliness Inspection ......................................................... 12

10.4 Bend Testing and Bend Test Sample Inspection........................................................ 13

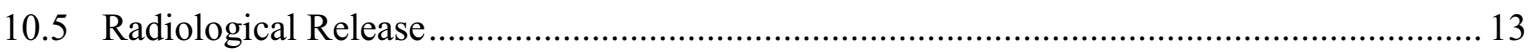

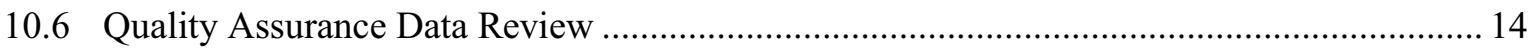

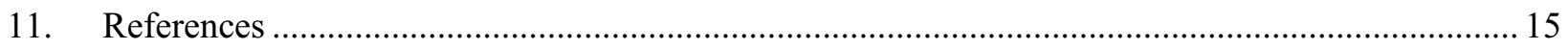




\section{FIGURES}

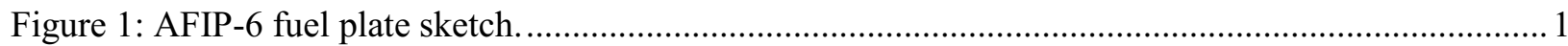

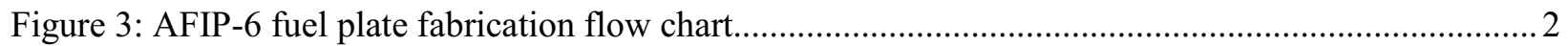

Figure 4: Image of AFIP-6 hot rolling assembly components prior to final lay-up and welding............... 4

Figure 5: Graph of rolling assembly thickness and maximum pass force during Zr / U-10Mo co-

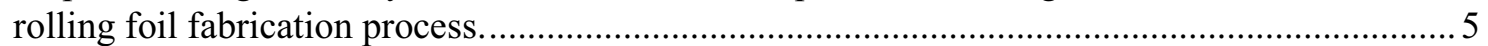

Figure 6: Hot rolling assembly after rolling and annealing and prior to foil removal. ............................ 5

Figure 7: Sheared and polished AFIP-6 Zr co-rolled U-10Mo fuel foil prior to clad bonding................... 6

Figure 8: Typical layout of a HIP can assembly ................................................................................... 7

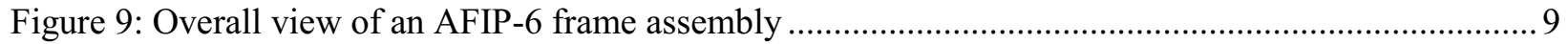

Figure 10: Example of Bend Testing Samples. No delamination (left), delamination (right).................. 13

\section{TABLES}

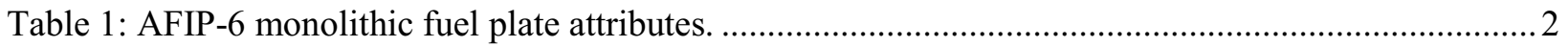

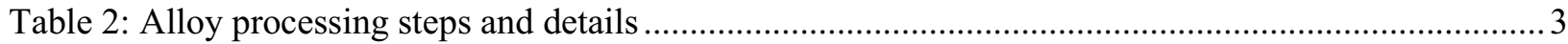

Table 3: Summary of Y-12 Data for As-Received U-10Mo Alloys incorporated into AFIP-6 Fuel

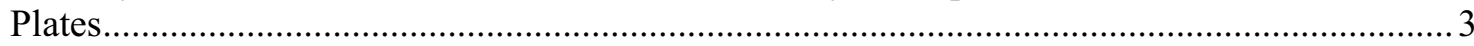

Table 4: Summary of Fuel Loading Acceptance Criteria and AFIP-6 Plate Data .................................. 11

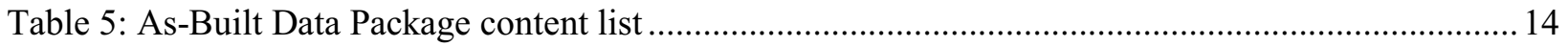




\section{ACRONYMS}

$\begin{array}{ll}\text { ABDP } & \text { As-Built Data Package } \\ \text { AFIP } & \text { ATR Full-size plate In center flux trap Position } \\ \text { ATR } & \text { Advanced Test Reactor } \\ \text { B\&W NOG } & \text { Babcock \& Wilcox Company Nuclear Operations Group } \\ \text { CFT } & \text { Center Flux Trap } \\ \text { DOE-NE } & \text { Department of Energy Office of Nuclear Energy } \\ \text { ECAR } & \text { Engineering Calculations and Analysis Report } \\ \text { FOZ } & \text { Fuel out of Zone } \\ \text { HEU } & \text { Highly Enriched Uranium } \\ \text { HIP } & \text { Hot Isostatic Press } \\ \text { INL } & \text { Idaho National Laboratory } \\ \text { MFC } & \text { Materials and Fuels Complex } \\ \text { NNSA } & \text { Nuclear Nonproliferation and Security Affairs } \\ \text { PLN } & \text { Plan } \\ \text { QC } & \text { Quality Control } \\ \text { QE } & \text { Quality Engineer } \\ \text { RERTR } & \text { Reduced Enrichment for Research and Test Reactors } \\ \text { SME } & \text { Subject Matter Expert } \\ \text { TEV } & \text { Technical Evaluation Report } \\ \text { TFR } & \text { Technical and Functional Requirements } \\ \text { UT } & \text { Ultrasonic } \\ \text { Zr } & \text { Zirconium } \\ & \end{array}$




\section{AFIP-6 Fabrication Summary Report}

\section{INTRODUCTION}

The AFIP-6 (ATR Full-size plate In center flux trap Position) experiment is designed to evaluate the performance of monolithic uranium-molybdenum (U-Mo) fuels at a scale prototypic of Advanced Test Reactor (ATR) fuel plates (45" long). Two qualified fueled plates were fabricated for the AFIP-6 experiment and subsequently inserted into the INL Advanced Test Reactor (ATR) for irradiation. An additional two plates were fabricated for archive purposes. Fuel plate and fuel plate assembly qualification requirements are established in TFR-662, Rev 0, "Specification For AFIP Fuel Plates And Assemblies For Irradiation In The ATR".

Fuel plate assemblies were prepared for irradiation in the Center Flux Trap (CFT) position of the ATR using the existing AFIP hardware. Each frame assembly afforded the irradiation of one fuel plate sample. Fuel plate frame assemblies were designated AFIP-6A and AFIP-6B. A sketch of each the fuel plate's critical dimensions is shown in Figure 1; taken from INL Drawing 759558, "ATR COMPLEX TRA-670 AFIP-6 FUEL PLATE DETAIL AND SECTION". Figure 2, shows the AFIP-6 plate frame assembly configuration; taken from INL Drawing 759557, "ATR COMPLEX TRA-670 AFIP-6 FUEL PLATE FRAME ASSEMBLY ASSEMBLY AND DETAILS".

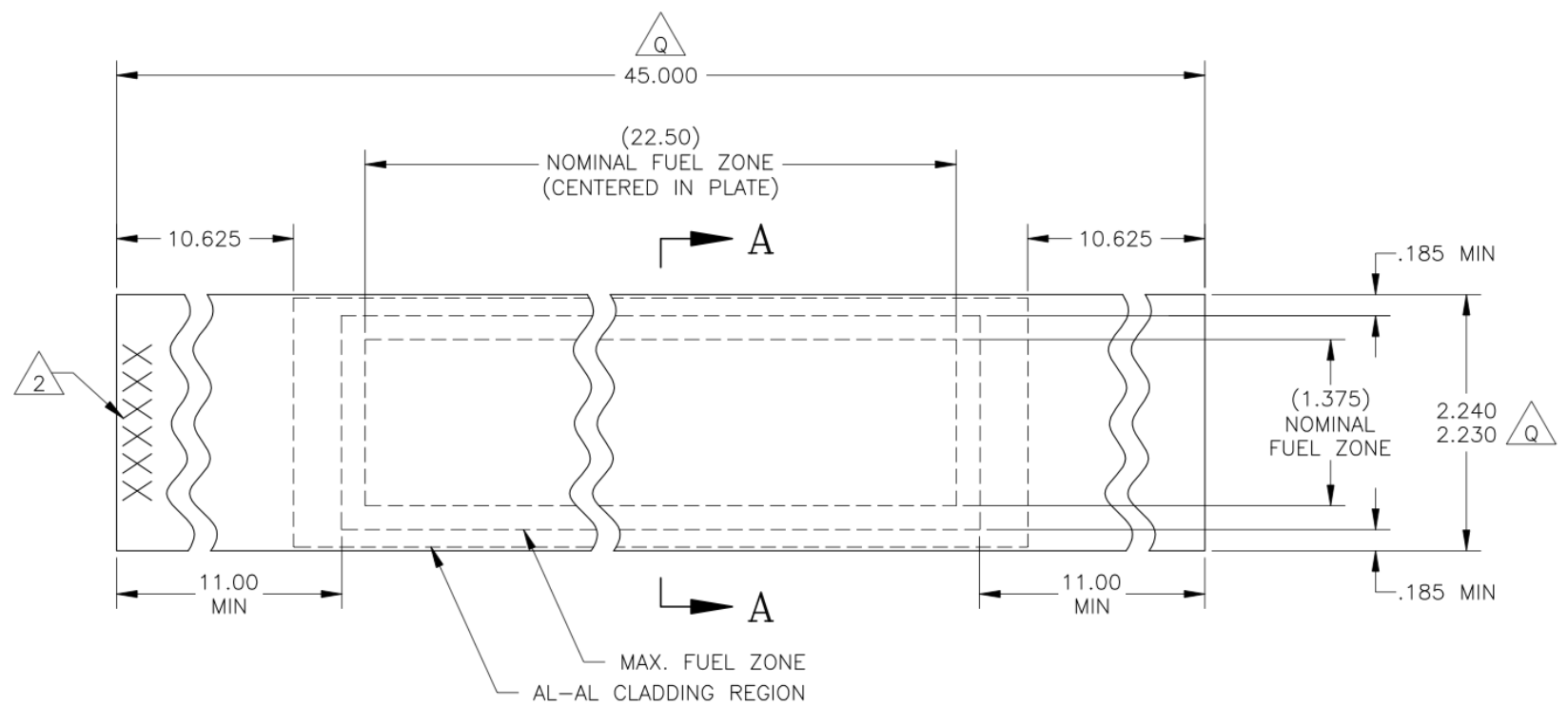

Figure 1: AFIP-6 fuel plate sketch.

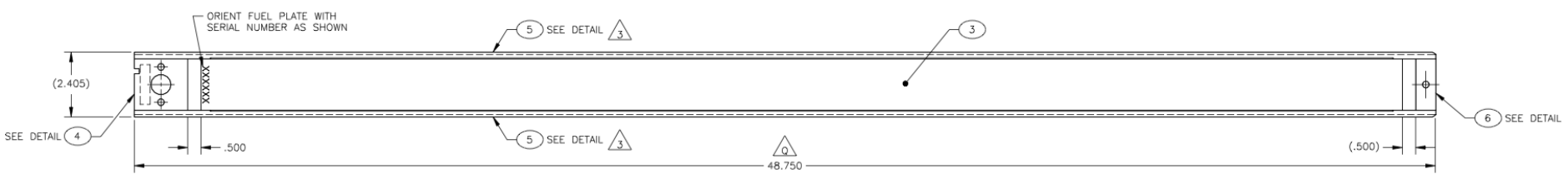

Figure 2: AFIP-6 plate assembly configuration.

The fuel phase in both fuel plates is U-10Mo at $\sim 40 \%$ U-235 enrichment, the fuel alloy coupons were supplied by the Y-12 National Security Complex. A zirconium diffusion barrier was applied to each fuel coupon via a hot rolling process. This produced a monolithic fuel foil with a nominal fuel thickness of 0.013-in with an additional 0.001 -in of $\mathrm{Zr}$ applied to both sides of the fuel yielding a total nominal foil thickness of 0.015-in. Fuel foils were clad with Al-6061 via the Hot Isostatic Pressing (HIP) process. 
Fuel plates were fabricated as described in PLN-3441, Fabrication Control Plan for the AFIP-6 Experiment. A total of four fuel foils were fabricated at the INL Materials and Fuels Complex (MFC) by the Reduced Enrichment for Research and Test Reactors (RERTR) Fabrication Group in the period of September 2009 to October 2009, after which the foils were shipped to B\&W Nuclear Operations Group (NOG), Lynchburg VA for HIP plate fabrication and final plate assembly processing. The B\&W NOG fabrication effort took place during the period of January 2010 to April 2010. The attributes of the AFIP6 fuel plates can be found in Table 1 .

Table 1: AFIP-6 monolithic fuel plate attributes.

\begin{tabular}{|c|l|}
\hline Plate Type & \multicolumn{1}{c|}{ Attributes } \\
\hline \multirow{3}{*}{ HIP } & - Uranium Molybdenum Fuel Alloy: U-10Mo nominal \\
& - Uranium Enrichment: $40.0 \mathrm{wt} \%$ U enrichment nominal \\
& $\begin{array}{l}\text { - Fuel Meat: } 0.013 \text { in. nominal Thickness, } 1.375 \text { in. nominal width, } 22.5 \text { in. nominal length } \\
\text { - Cladding: } 6061 \text { aluminum } \\
\text { - Reaction Barrier: } \sim 0.001 \text { in. thick Zirconium (Zr) layer applied to foil via hot rolling process on } \\
\text { both sides of foil. }\end{array}$ \\
\hline
\end{tabular}

A plate-fabrication process flow diagram is represented in Figure 3, where the shaded area represents the steps of the process that were performed at the INL.

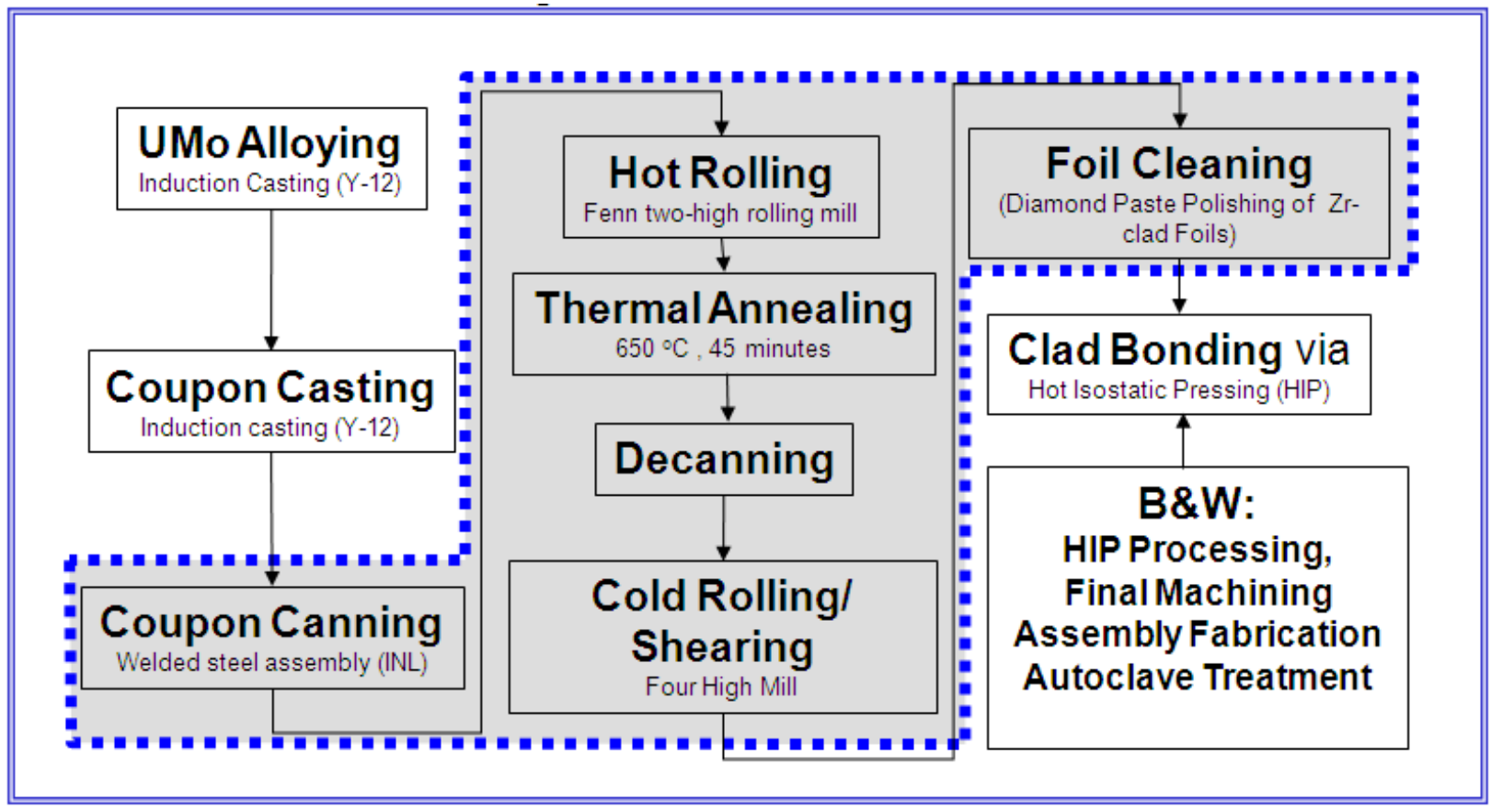

Figure 3: AFIP-6 fuel plate fabrication flow chart. 


\section{MATERIALS}

The U-10Mo fuel alloy material was supplied by the Y-12 National Security Complex (Y-12) in the form of machined HEU-10Mo coupons. A summary of HEU-10Mo alloy coupons preparation at Y-12 is established in Table 2.

Table 2: Alloy processing steps and details

\begin{tabular}{|c|l|}
\hline Alloy Processing Step & \multicolumn{1}{c|}{ Details } \\
\hline Pre-Melt Casting & $\begin{array}{l}\text { Induction melting and casting of HEU, Low-Assay Diluent (DU), Alloy } \\
\text { Material (Mo) in proportion to yield U-10Mo with nominally 40.0\% U- } \\
235 \text { enrichment. }\end{array}$ \\
\hline Final Casting & Induction melting and casting of U-10Mo alloy \\
\hline Coupon Machining & Machined coupons $\sim 4.5 \% \mathrm{~L} \mathrm{x} \sim 3.0 \% \mathrm{~W} \mathrm{x} \sim 0.14 \% \mathrm{~T}, \sim 500 \mathrm{~g}$ \\
\hline
\end{tabular}

Summary data of the as-received U-10Mo coupon material used to produce the AFIP-6 fuel plates is summarized in Table 3. The chemical analysis/certification documentation provided by $\mathrm{Y}-12$ can be found in INL Rec./Doc. ID AFIP-6: "AFIP-6 AS-BUILT DATA PACKAGE”.

Table 3: Summary of Y-12 Data for As-Received U-10Mo Alloys incorporated into AFIP-6 Fuel Plates

\begin{tabular}{|r|c|c|}
\hline \multicolumn{1}{|c|}{ Item/Data } & Coupon 3G60C7PA21 / Foils 344-1, -2 & Coupon 3G60C7PA23 / Foils 346-1, -2 \\
\hline Y-12 Analysis Number & Y091900022 & Y091900022 \\
\hline Mo (wt\%) & $9.84 \%$ & $9.84 \%$ \\
\hline Uranium Enrichment (wt\% U235) & $40.01 \%$ & $40.01 \%$ \\
\hline Carbon content (ppm) & 692 & 692 \\
\hline Nominal Coupon Size & & \\
\hline Weight (g) & $510 \mathrm{~g}$ & $450 \mathrm{~g}$ \\
\hline Length (in) & $4.5 \%$ & $4.5 \%$ \\
\hline Width (in) & $3.0 \%$ & $3.0 \%$ \\
\hline Nominal Thickness (in) & $0.14 \%$ & 0.13 " \\
\hline
\end{tabular}

\subsection{Cladding Material}

The cladding material used for the AFIP-6 fuel plates was Al-6061 in the T6 condition. The thickness of the aluminum sheet was 0.063 ".

\subsection{Zirconium Diffusion Barrier Material}

Alfa Aesar Zirconium Foil, 0.25mm (0.010”), 99.8\% metal basis. 


\section{FOIL FABRICATION OF ZR CO-ROLLED FOILS}

The foil fabrication process utilized is described in detail in INL/EXT-10-17774, "Co-Rolled U10Mo/Zirconium-Barrier-Layer Monolithic Fuel Foil Fabrication Process". A zirconium co-rolled fuel foil was used in the fabrication of all fuel plates. The foils were processed from a cast and machined U10 Mo coupon, nominally 4.5 " long x 3.0 "wide x 0.14 " thick. The long dimension of the coupon was parallel to the casting direction.

Prior to foil fabrication activities, the coupon edges and corners were rounded using a file in order to prevent breaching of the rolling can during processing. The alloy coupon was acid cleaned to remove any surface oxide contamination. A 30\% nitric acid solution was used, followed by a deionized (DI) water rinse, and an ethanol wipe down.

In the preparation of rolling assembly, two pieces of 0.010 " thick zirconium foil were sheared slightly larger than the coupon dimensions so as to completely overlay the coupon's faces within the rolling assembly. The inside surfaces of the top and bottom plates were coated with Neolube to prevent the zirconium foil from adhering to the assembly during hot rolling. Neolube coated plates were heated at $100{ }^{\circ} \mathrm{C}$ for ten minutes to remove residual solvent. The zirconium foils were cleaned with acetone prior to use and spot welded at the corners to keep the foils in place. The areas on the steel cover where the spot welding occurred were free from the Neolube coating.

The cleaned coupon was then placed into a previously prepared hot-rolling assembly made of low carbon steel as soon as possible after cleaning. The assembly consists of a top, bottom, and a picture frame midplate, each $\sim 0.14$ " thick. An example of a typical assembly can be seen as Figure 4, with the zirconium foil on the left plate and the HEU-10Mo coupon on the right. Internal surfaces and edges of the rolling assembly plates were brushed with a stainless steel brush, chucked in a drill press.

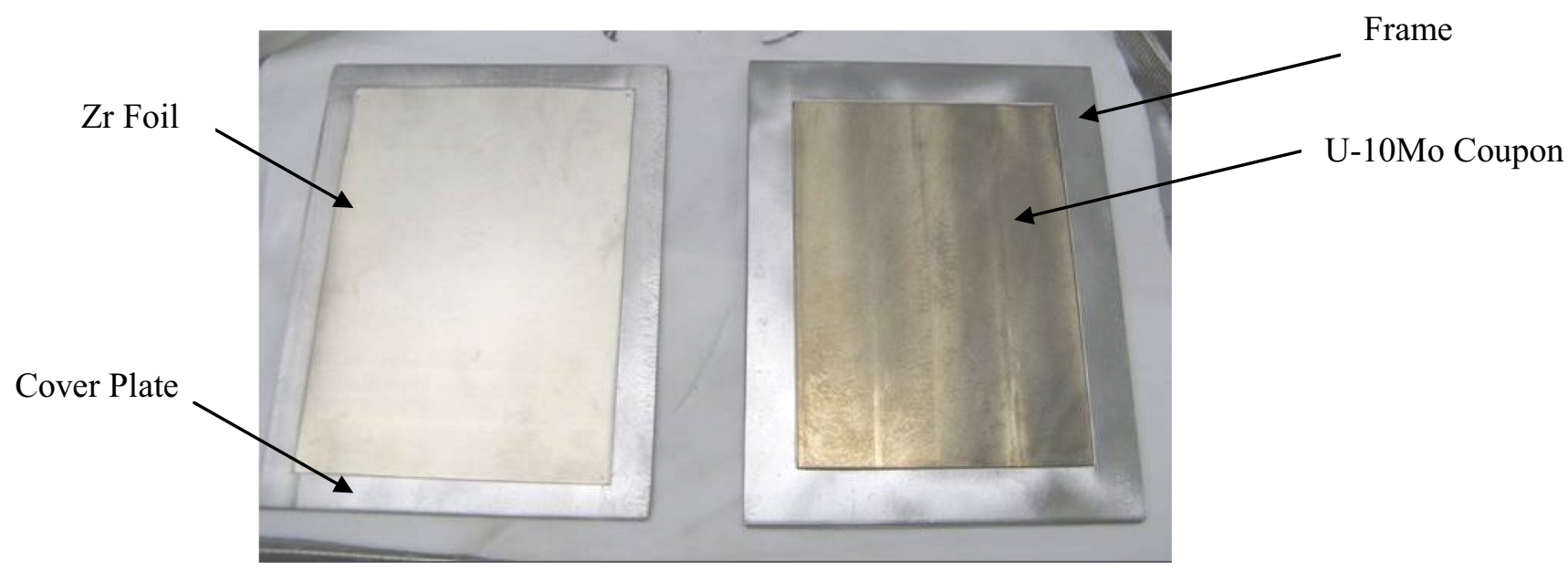

Figure 4: Image of AFIP-6 hot rolling assembly components prior to final lay-up and welding.

After lay-up, the rolling assembly was temporarily clamped together, moved to an argon atmosphere glove box and edge welded on all four sides.

The welded rolling assembly was preheated in a box furnace for 30 minutes at $650{ }^{\circ} \mathrm{C}$, after which, the assembly was removed from the furnace using tongs and passed through a computer controlled, hydraulically adjusted, two high rolling mill. The first set of passes, a reduction pass and a zero pass, were cross-rolled, a technique where the coupon was fed widthwise rather than lengthwise. This was performed to give additional width to the final foil so that after the foil could be cut in half lengthwise, 
resulting in two usable foils. The rolling assembly was then returned to the furnace and reheated for 15 minutes. The next three set of passes consisted of three reduction passes and a zero pass, after which the foils were reheated for 10-15 minutes. From this point on, the number of passes per set was reduced to a reduction pass and a zero pass followed by a five minute reheat. The roller speed was also reduced at the beginning of the last set of three reduction passes and a zero pass. During the course of the rolling process, the percent reduction, roller speed and reheating length and frequency were varied in order to minimize the introduction of ripples in the final foil.

An example of rolling assembly thickness reduction over time and maximum per pass force is shown in Figure 5. Each data point represents a set of passes, as was previously mentioned. It should be noted that the largest single pass reduction used was $20 \%$; with a range of $1-20 \%$ being employed.

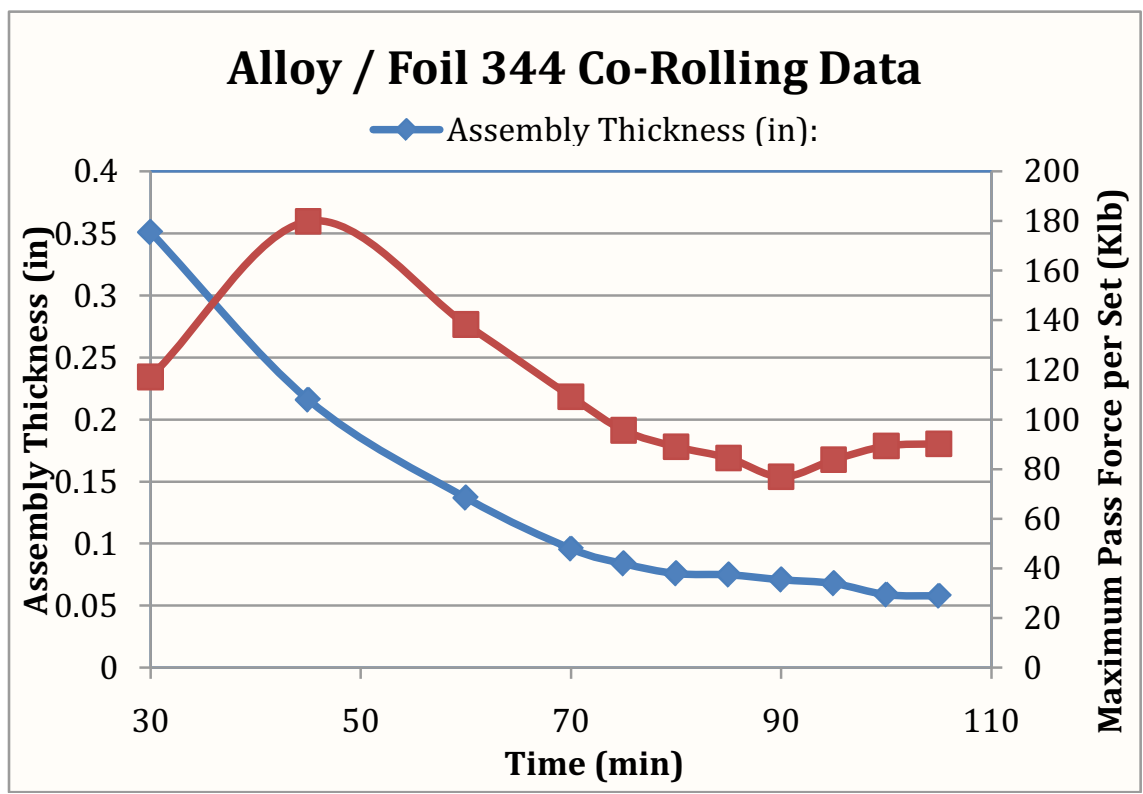

Figure 5: Graph of rolling assembly thickness and maximum pass force during $\mathrm{Zr}$ / U-10Mo co-rolling foil fabrication process.

After the rolling assembly was reduced to a thickness of 0.058 ", the $\mathrm{Zr}$ co-rolled foil, "still in the can", was annealed for $45 \mathrm{~min}$ at $650{ }^{\circ} \mathrm{C}$. Figure 6 shows an image of an annealed rolling assembly. Subsequently, the edges of the assembly were sheared away and the foil removed.

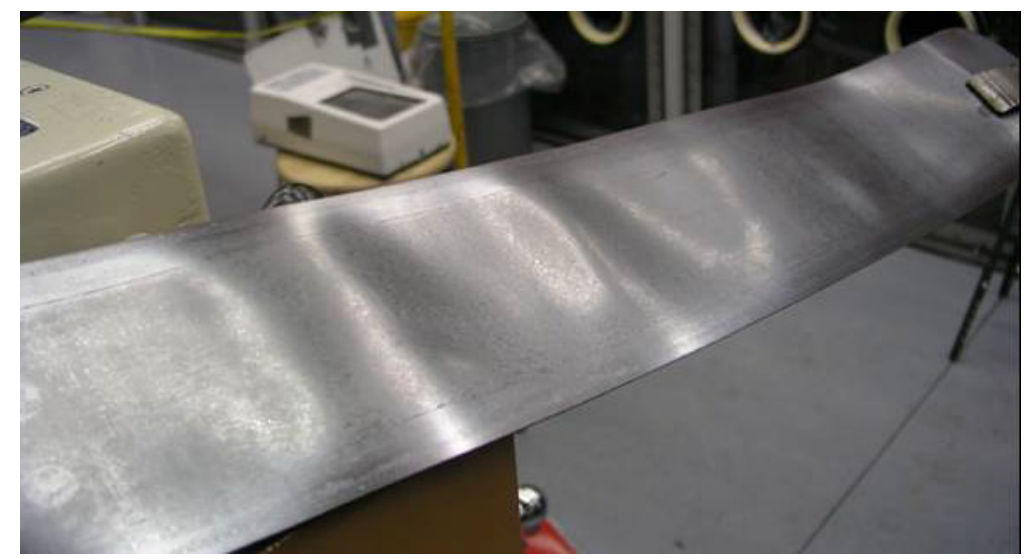

Figure 6: Hot rolling assembly after rolling and annealing and prior to foil removal. 
The obtained Zr-clad co-rolled fuel foil was cleaned with ethanol to remove any transferred carbon residue from the Neolube coated surfaces. The foil weight was measured in order to calculate the $\mathrm{wt} \% \mathrm{Zr}$ added. Foil dimensions were also obtained. A thickness of $30 \%$ greater than that required for the final fuel foil was the target of the co-rolling activity. This allows enough material to be able to remove any texturing or rippling of the foil that was introduced during the hot rolling process. The co-rolled foil obtained had the following nominal dimensions: 3.6" W x $251 / 4$ ” L x 0.022-0.025" T.

The co-rolled foil was trimmed and then sheared in half lengthwise after decanning and prior to cold rolling. The co-rolled foils obtained had the following nominal dimensions: 1.8 " W x 24 9/16" L x $0.022-$ 0.025 " T. The decanned foils were passed through a manual "screwdown" adjusted, four-high rolling mill. Each foil, 344-1, 344-2, was reduced to a nominal target thickness of 0.015", using seventeen to nineteen cold rolling pass sets, in which the foil underwent a reduction pass followed by two zero passes. Reduction of $\sim 0.0003$ " per set of passes was accomplished. As the thickness of the foils approach the final target thickness only zero passes were performed.

During the cold rolling of Foil 344-1, the process was stopped at a nominal thickness of 0.020 " and the foil was sheared into a 20 " piece and an 8 " piece. During the cold rolling of Foil 344-2, the process was stopped at a nominal thickness of 0.022 " and the foil was sheared into an 18.25 " piece and a 7.5 " piece. The two smaller pieces of foil were used in another study. Processing resumed on the two longer pieces until the final target thickness was achieved. Each of the two longer foil segments was sheared to the final AFIP-6 size establish in INL Drawing 759588. Thus, affording two fuel foils from the each of the original coupons.

After cold rolling, characterization samples were collected and foil thickness measurements were recorded, two rows of 24 data points each. The foils were polished using Amplex Superabrasives WS/HV 1226Y-1 \#30 MB $(30 \mu \mathrm{m})$ diamond polishing compound and wiped clean with ethanol and a lint free cloth. Cleaned/polished HEU10Mo Zr co-rolled foils were then sandwiched flat between plexiglass sheets, placed in a bag, and vacuum sealed.

After fuel-loading radiography was performed at the INL, foils were shipped to B\&W NOG for HIP plate fabrication. Upon receipt at $\mathrm{B} \& \mathrm{~W}$, isotopic verification samples were taken from each foil. The samples were taken from each end of each foil, and the reference end was maintained by clipping the corner on the same side of the foil as was clipped in the as-received foil. Final foil thickness measurements were obtained from each foil; two rows of 23 data points each. The foils were then wiped down with isopropyl alcohol and a clean cloth. Foil 344-1 was then polished using a diamond polishing compound. However, since there was no change in the appearance of the foil, no other foils were polished. Figure 7 shows a picture of an AFIP-6 Zr co-rolled U-10 Mo foil ready for clad bonding.

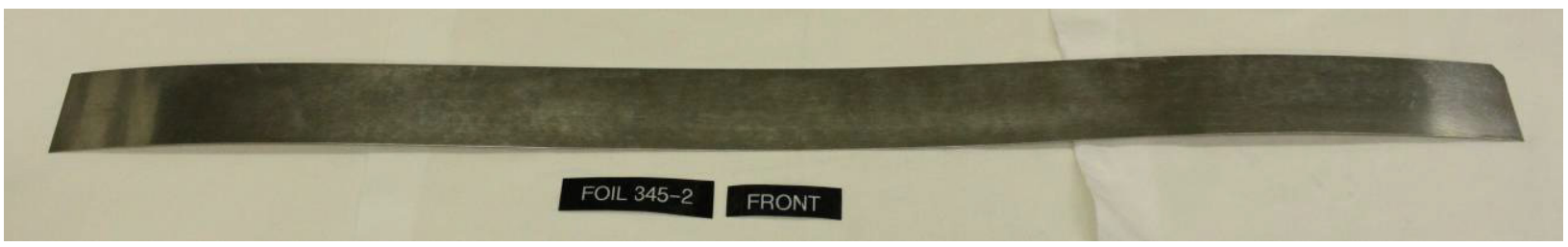

Figure 7: Sheared and polished AFIP-6 Zr co-rolled U-10Mo fuel foil prior to clad bonding. 


\section{CLADDING PREPARATION}

Cladding "Cover Sets" were prepared using Al-6061 sheet stock having a thickness of 0.063". Each set consisted of a top cover sheet and a pocketed bottom cover. Aluminum sheet stock was sheared and/or machined to needed length and width dimensions and a 0.016 " deep foil retention pocket milled in the pocket plate. After machining preparation, cladding sets were degreased and the to-be-bonded surfaces roughened using a coarse stainless steel wire brush. Cladding sets were then chemically cleaned, rinsed with isopropyl alcohol, and wiped clean of all dirt and debris.

Aluminum cladding "sets" used in HIP processing at B\&W were prepared as follows:

- As received sheets of Al-6061, with a nominal thickness of 0.063 " were sheared to desired size.

- A foil retention pocket was next milled into the "pocket plate" sheet material to a depth of 0.016 ". An isopropyl alcohol cutting fluid was used during the machining process.

- The cladding material was degreased to remove any grease, grit, and dirt.

- Roughening/abrading of the to-be-bonded surfaces of each cladding set using a coarse Stainless Steel wire brush.

- Cladding sheets were cleaned with Proceco cleaning solution (0.5 gal. of Triton DF-16 detergent (Dow Chemical) mixed into 250 gal. of deionized (DI) water), rinsed in hot DI water, then wiped with isopropyl alcohol until all dirt and debris is removed.

- The cladding receives an additional chemical cleaning step in a pickling solution made up of 32.5 gal. of nitric acid ( $70 \%$ concentration) and 4 gal. of hydrofluoric acid (49\% concentration) in 130 gal. of de-ionized water. The pickling time is adjusted to meet the metal removal requirement. This is followed by a hot water rinse.

\section{HIP PROCESSING FUEL PLATE FABRICATION}

The HIP process is used to hermetically seal a prepared fuel foil between two layers of Al-6061 cladding. A detailed description of fuel plate fabrication via the HIP process is reported in INL/EXT 10-17792, "INL HIP Plate Fabrication." Preparation of a HIP can assembly containing two AFIP-6 size HIP plate samples was performed. Samples consisted of a prepared HEU-10Mo fuel foil and a set of prepared Al6061 cladding sheets/plates; the "Pocket plate" was differentiated by having a pocket depth of 0.016 " machined in the material.

The layout of the HIP can assembly can be seen in Figure 8. Not shown in the figure is the detail that the individual U-Mo plates are comprised of two pieces of Al-6061, a pocket piece and a cover piece. Each sample was separated in the HIP can assembly by a mild steel "strong back"; thus facilitating near uniaxial pressure on the faces of the cladding sheets during processing. The steel "strong backs" were coated with a colloidal graphite release agent (Neolube \#1) to prevent them from bonding to the aluminum plates.

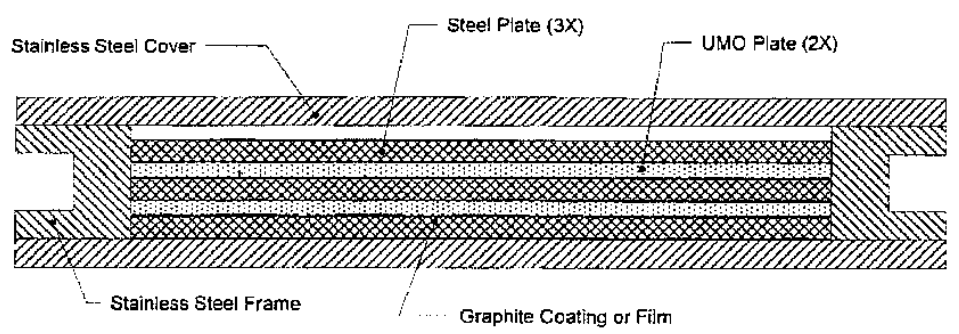

Figure 8: Typical layout of a HIP can assembly 
Two fuel plates were processed in each HIP can. HIP can preparation involved the following steps.

1) All HIP can components were cleaned by wiping them down with Proceco cleaning solution ( 0.5 gal. of Triton DF-16 detergent (Dow Chemical) mixed into 250 gal. of deionized (DI) water), rinsed in hot DI water, then wiped with isopropyl alcohol.

2) The Neolube coated steel "strong back", cladding and foils are stacked in the HIP can in the following order:

1. Steel "Strong Back"

2. Cladding Pocket Plate (pocket side up)

3. Foil is placed in the Pocket

4. Cladding Cover Plate (brushed surface faces the foil)

Process was then repeated for the second foil. Then the whole process was repeated for the second HIP can.

3) The HIP cans were then clamped together into the final configuration. The spring clamps used were placed on alternate sides of the assembly, approximately 8 " apart, centered on the middle of the plate.

4) The HIP cans were tack welded together. Two tack welds, approximately $1 \frac{1}{2}$ " from the center of the HIP can were applied on each end of the HIP cans followed by three to four evenly spaced tack welds applied to each edge of the HIP cans. The tack welds were lightly brushed to remove oxidation. Care was taken to avoid pushing debris between the HIP can cover plate and frame.

5) The edges of the HIP cans were welded together without filler metal.

6) The assembled HIP cans were leak checked with helium gas. No leaks were detected.

7) The HIP cans were vacuum degassed at $610^{\circ} \mathrm{F}\left(321^{\circ} \mathrm{C}\right)$ for $2 \frac{3}{4}-3$ hours, after which they were allowed to air cool while remaining under vacuum.

8) The evacuation tube of the HIP cans was crimp sealed, by heating the tube and crimping the tube shut in three places approximately 1" apart. The tubing was cut after the final crimp and the end of the tube welded closed.

HIP processing was accomplished using the same processing parameters that have been used in previous fabrication work. The can was subjected to a temperature of $560^{\circ} \mathrm{C}\left(+0 /-12^{\circ} \mathrm{C}\right)$ and a pressure of $15 \mathrm{ksi}$ (+/- $1 \mathrm{ksi})$ for $95 \mathrm{~min} .(+10 /-0)$ minutes. The processed HIP plates were retrieved via machining away several HIP can welds and disassembling the can.

\section{FINAL PROCESSING SEQUENCE}

After HIP plates were removed from the HIP, the edges were sheared to near final width. A fluoroscope and a fuel plate template were then used to guide indexing of the fuel zone region of each HIP plate. The template was centered, both lengthwise and widthwise, over the fuel core in order to locate and punch two reference holes 54.50" apart down the length of the plate. The plates were rough sheared to a width of $2.77 \pm 1 / 8$ " and a length of 49.50". The shear drop material was marked set aside for subsequent bend testing; the origin-location of each shear drop was recorded and the edge nearest the fuel plate marked.

Plates were later machined to a width of $2.235 \pm 0.005$ " and a length of 45.000 ". Radiography was performed on the plates in between shearing and machining of the width and length. Both location and density radiographs were taken. The location radiographs were used to determine the layout of the final dimensions of the plate. 
Ultrasonic (UT) characterization was performed in order to measure the cladding thickness and to detect the presence of any possible debonds in the processed plates. Based on the thickness of cladding above the fuel foil, as established with UT characterization, the fuel plates were machined on both sides to an overall thickness of $0.050 \pm 0.003$ " with a minimum cladding thickness of 0.006 " over the fuel foil. The cooling fluid used during this process is a 1:40 mixture of Hangsterfer's S-500 CF and water (1 pint of S500 to 5 gal. of water). After machining the plates, a $\sim 0.005$ " deep plate identification engraving was applied and the plates were wiped down with isopropyl alcohol.

Void volume testing was performed on the final sized plates. Thickness measurements were taken over the fuel zone region using a measurement point location template.

\section{FUEL PLATE ASSEMBLY}

Two fuel plate frame assemblies were qualified for the AFIP-6 experiment, A and B, per INL Drawing 759557, “ATR COMPLEX TRA-670 AFIP-6 FUEL PLATE FRAME ASSEMBLY ASSEMBLY AND DETAILS".

Prior to swaging, fuel plates and frame assembly hardware were chemically cleaned via the pickling solution used to clean the cladding material prior to HIPping. Approximately 0.0002" of cladding thickness is removed with cleaning and a like thickness reestablished during autoclaving.

After passing required QA evaluations, established in TFR-662, each of the two finished plates were swaged into side rails to form the AFIP-6 test assemblies. Pull test samples were made both before and after the swaging of each plate. A pull test was performed on these samples. A failure $(150 \mathrm{lb} / \mathrm{in}$ or lower) of any sample would result in the disassembling of the AFIP-6 plate assembly, readjusting the settings and re-swaging the plate assembly and new pull test samples. During the swaging process, the plates were flooded with isopropyl alcohol to provide lubrication. There were some minor swaging defects on the bottom of the first swaged assembly that had a cosmetic impact only. These were then hand worked prior to further processing. "Details" A photo of a complete fuel plate frame assembly can be seen as Figure 9.

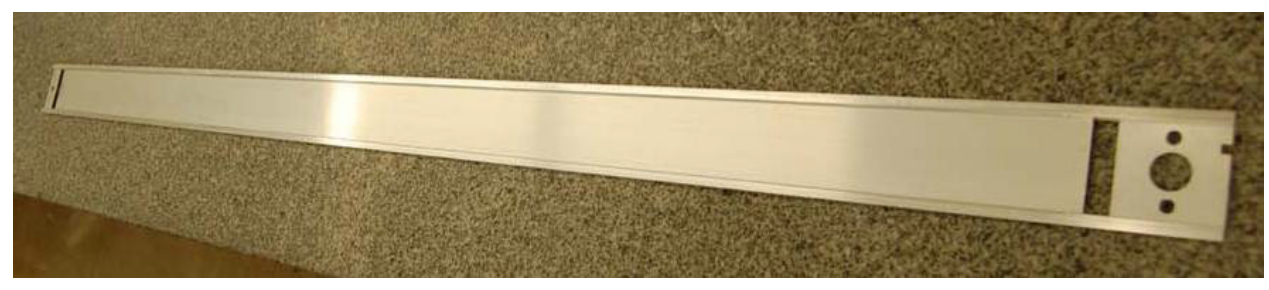

Figure 9: Overall view of an AFIP-6 frame assembly 


\section{OXIDE COATING APPLICATION}

An oxide film "beohmite" was applied to the fuel plate assemblies using an autoclave treatment; the coating or pre-film serves as a cladding corrosion inhibitor during irradiation testing.

The two fuel plate assemblies were fully immersed in demineralized water, with a $\mathrm{pH}$ between 5.0 and 8.0 , within the autoclave, with only their edges in contact with the plate holder. The oxide film was produced via an $18( \pm 2)$ hour hold at $365( \pm 27){ }^{\circ} \mathrm{F} / 185( \pm 15){ }^{\circ} \mathrm{C}$. Boehmite pre-film thickness measurements were obtained from the included test coupon using an eddy current type film thickness measurement device. The average of the eight thickness readings were reported as 0.00010 "; within the min-max range of 0.00006 "- 0.00030 ”.

Following the oxide film treatment, a cleanliness inspection was performed. The two prepared fuel plate frame assemblies were then packaged and shipped to the INL for irradiation.

\section{FUEL PLATE QUALITY ASSURANCE}

Candidate fuel plates were subjected to final inspections, evaluations, and characterization relative to fuel loading, ultrasonic (UT) characterization, fuel out of zone (FOZ) radiography, dimensional and surface cleanliness, bend test and radiological release, as established in TFR-662. The results were compiled and reviewed by the assigned INL Quality Engineer (QE). Two fuel plate frame assemblies were qualified for the AFIP-6 experiment. A summary of the quality assurance/qualification activities/efforts performed is provided below. Fabrication and qualification data may be found in the AFIP-6 AS-Built Data Package, INL Rec/Doc Id: AFIP-6.

\section{FUEL LOADING}

This section summarizes fuel loading calculations performed for AFIP-6 fuel plates. Fuel loading calculations for AFIP-6 irradiation experiment are detailed in "Fuel Loading Calculations for the AFIP-6 Irradiation Experiment, ECAR-929" report.

Candidate fuel foils were submitted to the MFC Quality Assurance (QA) services for radiography; prior to fuel foils being sent to B\&W NOG. Radiographs were obtained in the presence of a U-10 Mo tabbased reference standard. Densitometric measurements of radiographs were acquired by qualified MFC QA personnel per TFR-662 "Specification for AFIP Fuel Plates and Assemblies for Irradiation in the ATR". Measurements were taken using a commercial radiographic densitometer configured with a $3 \mathrm{~mm}$ diameter aperture. Five measurements were taken on each applicable step tab of the standard and 60 measurements were taken in the fuel zone region, in three rows of 20 measurements. The methodology used in performing interpretation of radiographic density data is based on establishing a trend line equation using the density measurements of the tab standard. The mean value of the measurements taken for each of the tabs is the $\mathrm{x}$ axis and the actual thickness value of each of the tabs is the $\mathrm{y}$ axis. A polynomial trend line equation was then established and applied to densitometric measurements associated with the fuel foil; resulting in equivalent thickness values for each data point. Equivalent thickness values were then compared to the established fuel loading acceptance criteria. Namely, the maximum allowable calculated thickness at any data point is 0.016 " and the maximum allowable average calculated thickness for the overall plate is 0.016 , as can be seen in Table 4. 
Table 4: Summary of Fuel Loading Acceptance Criteria and AFIP-6 Plate Data

\begin{tabular}{|c|c|c|c|c|}
\hline \multicolumn{5}{|c|}{ Fuel Loading Criteria } \\
\hline \multicolumn{4}{|c|}{ Maximum Allowable Calculated Thickness (each data point) } & $0.01575 ”$ \\
\hline \multicolumn{4}{|c|}{ Maximum Allowable Average Calculated Thickness (each plate) } & $0.01575^{\prime \prime}$ \\
\hline Foil ID & Plate ID & Ave. Thick. (in) & Maximum Thickness (in) & Minimum Thickness (in) \\
\hline Foil 344-1-1 & & 0.0134 & 0.0150 & 0.0113 \\
\hline Foil 344-2-1 & & 0.0137 & 0.0155 & 0.0106 \\
\hline Foil 345-1 & $6 Z \mathrm{ZF}-1$ & 0.0133 & 0.0150 & 0.0109 \\
\hline Foil 345-2 & $6 Z \mathrm{ZF}-2$ & 0.0132 & 0.0150 & 0.0107 \\
\hline Foil 346-1 & & 0.0137 & 0.0153 & 0.0113 \\
\hline Foil 346-2 & & 0.0137 & 0.0152 & 0.0114 \\
\hline
\end{tabular}

All candidate fuel plates were determined to have no fuel loading regions above the maximum allowable calculated thickness (for each data point acquired) and an average fuel loading below the maximum allowable average thickness; as reported in "Fuel Loading Calculations for the AFIP-6 Irradiation Experiment: ECAR-929".

\subsection{Ultrasonic Testing}

This section summarizes the results of the ultrasonic testing (UT) of AFIP-6 fuel plates. A more detailed description of the UT characterization results can be found in TEV-876, "AFIP-6 Fuel Plate Ultrasonic Debond And Min-Clad Thickness Test Results".

UT Characterization of candidate AFIP-6 fuel plates was performed at B\&W NOG using a workstation consisting of a water tank, sample holder, UT scanning hardware, and a data acquisition system. The data acquisition system used standards based inspection/evaluation system. Two types of scans are acquired: 1) Debond scan that yields a single image/maps of ultrasonic signal transmission through a sample, and 2) Min clad scan that yields a series of images, via time-of-fight analysis/process of back reflections, representative of "reflection features" at a given depth from each face (near and far) of a sample. Reflection features arise from interfaces, inclusion, and/or voids. Both types of scans can be acquired simultaneously.

The debond image/data was considered "for information only", but acquired using a calibrated system. Calibrated reference standards were used to validate the system both before and after the inspection/evaluation.

The min-clad inspection data was used for acceptance of meeting the fuel specification requirement for minimum cladding. Namely, the cladding thickness above the fuel zone region of each fuel plate shall be determined using UT characterization. Each fuel plate shall be subjected to a minimum cladding UT scan. Traceable references standards are used to verify the min-clad system calibration before and after the fuel plate was characterized. The min-clad standard was an aluminum plate having engineered voids with known depths and diameters. Specifications for minimum cladding requirements are stated in Drawing 759558, "AFIP-6 Fuel Plate," where the minimum cladding thickness callout was as 0.006 in..

When describing information obtained from UT characterization/analysis, near side and far side reference was made relative to plate orientation in the UT tank. It was administratively established that a fuel plate sample was mounted for characterization with the ID stamp on the front (loading side) and right side of the established sample holder (thus the "front side of the 
plate" having the plate ID engraving was designated as the near side and the non-engraved side of the fuel plate was referenced as the "far side").

Acquired UT characterization data was submitted to the INL UT characterization SME, Steve Taylor, for preparation of a Technical Evaluation Report (TEV). Evaluation findings are reported in TEV-876, "AFIP-6 Fuel Plate Ultrasonic Debond and Min-Clad Thickness Test Results."

All AFIP-6 fuel plates meet the requirements listed in TFR-662 Rev. 0 "Specification for AFIP Fuel Plates and Assemblies for Irradiation in the ATR" for min-clad and debond.

\subsection{Fuel Out of Zone Inspection}

Fuel out of zone (FOZ) inspection was employed for the purpose of ensuring that any stray particles outside of the maximum fuel region and plate edges and ends, as defined in INL Drawing 759558, "AFIP-6 Fuel Plate", do not violate the established acceptance criteria. Specifically, stray fuel particles are allowed provided they are not within $0.020 \mathrm{in}$. of the edge of the fuel plate.

The FOZ inspection was conducted by a qualified inspector using the following:

- Using a 5x magnifier

- Transparency template of the fuel plate perimeter and maximum fuel zone

- Radiograph(s) of the fuel plate acquired using conditions that yield high contrast of the fuel material and showing the plate's perimeter.

Both AFIP-6 plates met the FOZ acceptance requirements.

\subsection{Dimensional, Surface, and Cleanliness Inspection}

The dimensional and surface inspection was conducted by a qualified inspector using the fuel plate drawing, INL Drawing 759558. The minimum and maximum values of the length and width were recorded, as well as forty-six thickness measurement values; for future use in establishing irradiated plate swelling. This data is recorded on the Fuel Plate Summary Sheet for each fuel plate, see AFIP-6 As-Built Data Package, INL Rec/Doc Id: AFIP-6

The criteria established for the visual cleanliness inspection are as follows:

- "Surface defects: such as scratches, marks, grooves, pores and other surface flaws greater than $0.203 \mathrm{~mm}(0.008 \mathrm{in})$ deep and residing over the fuel zone, shall be cause for rejection".

- The surface roughness shall be in accordance with INL drawing 759558.

- Cleanliness of the fuel plate shall be in accordance with INL STD 7022, Level C.

Both AFIP-6 plates met the established dimensional, surface, and cleanliness inspection requirements. 


\subsection{Bend Testing and Bend Test Sample Inspection}

Bend testing was utilized to insure that aluminum to aluminum bond of the cladding material around the perimeter of the fuel zone region was adequately bonded. The bend test consists of the following steps:

- Acquiring samples from all sides of each plate. At least twelve bend samples adjacent to each plate (including five along each long side and one along each short side).

- Marking the samples such that the edge nearest the fuel plate was established.

- Clamping each sample in a test fixture and bending the sample around a $\sim 0.125$ " radius/mandrel 90 degrees from the starting position, returning the sample to the initial position, bending the sample 90 degrees in the other direction, and returning the sample back to the original position.

- Bend test samples are visually inspected, by a qualified inspector, for any visual delamination of the edge indicated as adjacent to the fuel plate. Examples of both delaminated and not delaminated samples can be seen in Figure 11.
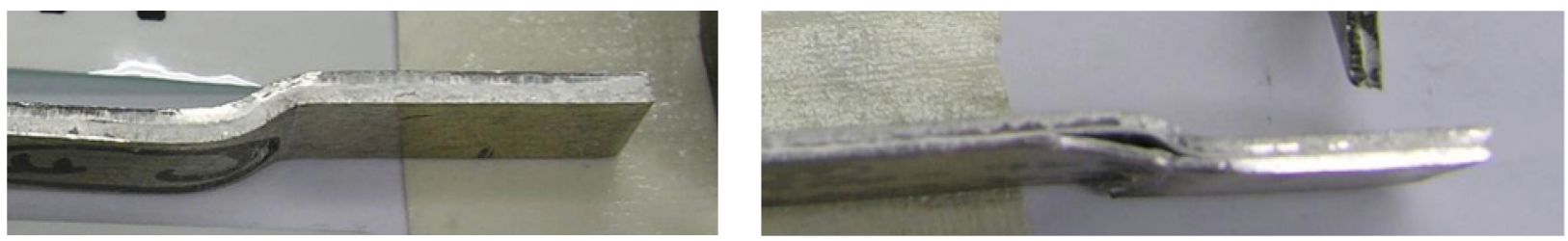

Figure 10: Example of Bend Testing Samples. No delamination (left), delamination (right).

All AFIP-6 bend test samples met the acceptance criteria established. Namely: no visual delaminations of the cladding were observed in any of the "at least six bend samples (including two along each long side and one along each short side."

\subsection{Radiological Release}

Prior to and after fuel plate assembly, radiological smears of fuel plates and assembly components were obtained and evaluated for radiological contamination. Both AFIP-6 fuel plate assemblies were determined to be free of contamination and released for packaging and shipment to the INL. 


\subsection{Quality Assurance Data Review}

Qualification of fuel plates was accomplished via the preparation of an As-Built Data Package, INL Rec/Doc Id: AFIP-6. The As-Built Data Package contains documentation for each data/quality element required by the Fuel Specification. A list of these elements is provided in Table 5. After review of the prepared As-Built Data Package, by the INL assigned Quality Engineer (QE), a "Green Tag" for each fuel plate frame assembly was issued.

Table 5: As-Built Data Package content list

\begin{tabular}{|l|}
\multicolumn{1}{|c|}{ As-Built Data Package Content List } \\
\hline As-Built Data Package Summary \\
\hline Fuel Specification \\
\hline Experiment Control Plan \\
\hline Fabrication Control Plan \\
\hline Drawings \\
\hline QA Checklist \\
\hline Bend Test Sample Inspection Report \\
\hline Fuel out of Zone (FOZ) Inspection Report \\
\hline Plate Dimensional Inspection Report \\
\hline Radiological Survey \\
\hline Frame Assembly Documentation (including Green Tags) \\
\hline Dimensional and Visual Inspection / Autoclaving Move Ticket \\
\hline Materials Certifications \\
\hline Foil Final Dimensions Data Sheet \\
\hline Cladding Verification \\
\hline Alloy Tracking Spreadsheet \\
\hline Foil Verification \\
\hline Zirconium Verification \\
\hline Surface Defect and Cleanliness Inspection Report \\
\hline Plate Summary Sheet \\
\hline Assembly Loading Documentation \\
\hline Immersion Density Activity Sheet \\
\hline Autoclave Run Record \\
\hline HIP Run Data Sheet \\
\hline Swage Joint Sample Pull Test Results \\
\hline Green Tags \\
\hline
\end{tabular}




\section{References}

PLN-3222 “Experiment Control Plan for the AFIP-6 Fuel Irradiation in the ATR” Rev. 1, 11/3/09

PLN-3441 "Fabrication Control Plan for the AFIP-6 Experiment" Rev. 0, 3/24/10

TFR-662 "Specification for AFIP Fuel Plates and Assemblies for Irradiation in the ATR" Rev. 0, 3/8/10

AFIP-6 As-Built Data Package, Rec/Doc Id: AFIP-6, 04/06/2010

ECAR-929 "Fuel Loading Calculations for the AFIP-6 Irradiation Experiment” Rev. 0, 3/25/10

TEV-876 “AFIP-6 Fuel Plates Ultrasonic Debond and Min-Clad Thickness Test Results” Rev. 0, 8/31/10

INL Drawing 759558, “ATR COMPLEX TRA-670 AFIP-6 FUEL PLATE DETAIL AND SECTION”.

INL Drawing 7595587, “ATR COMPLEX TRA-670 AFIP-6 FUEL PLATE FRAME ASSEMBLY ASSEMBLY AND DETAILS”.

INL Rec/Doc Id., "AFIP-6 Fabrication: B\&W Final Report"

INL/EXT 10-17774, "Co-Rolled U10Mo/Zirconium-Barrier-Layer Monolithic Fuel Foil Fabrication Process", 1/28/2010.

INL/EXT 10-17792, “INL HIP Plate Fabrication”, 2/3/2010 